\title{
Editorial
}

\section{School - a multitude of opportunities for promoting healthier eating}

Strategies to counteract the burden of nutrition-related disorders and unhealthy eating patterns at the national level are commonly based on regulatory approaches, but a growing number of strategies are also targeting the local level. School-based strategies are among the most promising, and the growing interest in school-based public health nutrition strategies is reflected in the growing number of contributions to Public Health Nutrition. A count of papers published in this journal shows that those dealing with food and nutrition at school have grown exponentially since the beginning of the new millennium.

Cluster-randomized studies provide increasing evidence for the idea that school-based nutrition interventions can positively impact the eating patterns of children and in some cases even indicators of health status. A number of studies have also shown that the school meals offered tend to be more in compliance with current nutritional recommendations than alternatives brought from home or outside the school. This growing evidence base has helped spawn a new interest in school-based nutrition strategies among policy makers. The Council of Europe Resolution on healthy eating at school ${ }^{(1)}$, the Nordic action plan on diet and physical activity ${ }^{(2)}$, the European Charter on counteracting obesity adopted at the WHO European Ministerial Conference in $2006^{(3)}$, as well as the EU White Paper on diet and physical activity ${ }^{(4)}$ are all examples of this emerging interest at the intergovernmental policy level. The Nutrition Friendly Schools Initiative taken by WHO, the EU School Fruit Scheme from 2009, as well as the recent inventory published by the World Food Programme ${ }^{(5)}$ on school feeding across the world are other examples of the recent emphasis on school-based food and nutrition programmes and interventions as population-based strategies.

From being a 'mundane activity in prosaic settings'(6) of little societal interest, public catering and in particular school meal programmes (SMP's) have made their way into higher places. US First Lady Michelle Obama and former British Prime Minister Tony Blair have both shown serious interest in improving the nutritional quality of their own country's SMP's. Likewise, a growing number of European countries have adopted guidelines on the nutritional composition of school lunches in response to the recognition that foods and drinks of poor nutritional quality were being marketed in schools with only little regulation $^{(7)}$.

\section{A broad range of challenges and strategies}

This issue of Public Health Nutrition highlights work from the global research community that advances scientific investigations on the potential contributions of schoolbased nutrition initiatives to public health. The articles come from a wide range of countries including Germany, Switzerland, Denmark, Norway, Portugal, England, Wales, the USA, Chile, Brazil and South Africa, and they represent a broad spectrum of scientific approaches.

\section{Choosing among bealtby and unbealtby food options}

Schools can be useful settings for behavioural interventions targeting school-aged children. Ribeiro et $a l^{(8)}$ compared two school-based programmes for health behaviour change in the Belo Horizonte Heart Study, Brazil. In a randomized trial using a Stages of Change approach, they found that the intervention was able to move students into the preparation, action and maintenance stages of a healthy lifestyle as indicated by fatty food consumption, fruit and vegetable consumption, physical activity and time spent away from sedentary activities.

Other studies in this issue deal with the challenge of how to encourage healthy food choices in an environment that includes unhealthy options. In a diverse school foodscape, the battle between healthy and unhealthy options is a serious challenge since the meal that school offers may have to compete against foods from other sources that might not comply with nutritional recommendations. In their exploration of the topic of 'competitive foods' in a low-income school district in California, USA, Caparosa et $a l^{(9)}$ found that a substantial amount of unhealthy foods and beverages were brought into school for classroom rewards, celebrations and fundraising. In their study of poorly resourced schools in South Africa, Faber et al. ${ }^{(10)}$ similarly described a complex school foodscape with many challenges to healthy eating at school, especially from competitive foods.

School fruit and vegetable schemes provide an opportunity to promote healthier options in the school food environment. Analysing representative data from a Norwegian school fruit natural experiment, for example, Øvrum and Bere $^{(11)}$ found that a free school fruit programme was associated with increased fruit intake by the child, and perhaps even by the parent. In their experimental study, Bucher et $a l^{(12)}$ found that simply increasing vegetable 
variety (two vegetables versus one) at a food buffet increased vegetable choice among children. Influencing food choice dynamics in schools is another potentially promising way to influence students' eating habits. In a previous issue, Just and Price ${ }^{(13)}$ had studied the impact of default options and incentives among elementary-school children and found that placement combined with the use of incentives were effective in increasing the students' intake of fruit and vegetables.

\section{School meal programmes}

The development and implementation of SMP is addressed in the contribution from Valaitis et $a l^{(14)}$. They studied perceptions of strengths, weaknesses, opportunities and threats associated with school nutrition programmes among SMP coordinators. The SMP they studied varied enormously in terms of foods and services offered, and in terms of the perceived needs among students who received those foods and services. These authors report those perceptions in terms of strengths - such as universality (the ability to reach needy students) and the provision of social opportunities and in terms of weaknesses - such as challenges in forming funding partnerships, lack of volunteers, scheduling and timing issues, and coordinator work-load.

Use of standards as a tool to increase the nutritional quality of school lunches is a popular strategy in many countries. But the study reported by Smith and CunninghamSabo ${ }^{(15)}$ showed that standards alone may not do the job. They found that few students' lunches met either previous standards or the new, strengthened US National School Lunch Program standards. They concluded that effective behavioural interventions, combined with marketing, communications and behavioural economics instruments could be used to encourage greater vegetable intake to meet the new standards. Rocha et $a l^{(16)}$ also touch on the topic of planning and evaluating the nutritional quality of the school meals. They describe the SPARE software developed to plan and evaluate school meals in Portugal, with good results.

Examining factors that influence uptake of school meals among pupils is important in schools in which meals are not necessarily taken by all students. In their study of the uptake of free school meals in primary- and secondary-school children in England, Sahota et al. ${ }^{(17)}$ found that the registration process related to free school meal entitlement was perceived as a barrier and that anonymity should be secured. Their study emphasizes the importance of the whole school environment and suggests that attention should be given not only to the quality and availability of food, but also to the social, cultural and environmental dimensions of dining.

The social gradient in health is also addressed in the paper by Moore et al. ${ }^{(18)}$ taking as a point of departure the assumption that a consistent and healthy school foodscape should include not only the lunch but also breakfast. Moore et $a l .{ }^{(18)}$ studied the impact of the Free Breakfast Initiative in primary school on socio-economic inequalities in breakfast consumption among 9-11-year-old pupils in Wales. They found that the children in schools that provided free breakfasts ate a greater number of healthy items for breakfast than children in control schools. The authors concluded that providing breakfast may help reduce socioeconomic inequalities in consumption of healthy breakfast items and in breakfast skipping.

\section{School nutrition policies}

The school itself is influenced by external factors, and in this issue Vine and Elliott ${ }^{(19)}$ identify food costs and in-school as well as out-of-school competitive food opportunities as some of the local-level factors that play a role in shaping or affecting the implementation of school nutrition policies in Ontario, Canada. Another study explored the influence of public organic food procurement policies on school food environments. School programmes and interventions are increasingly looking beyond the healthiness of food itself and are targeting the sustainability of the food supply chain, and this study represents an example of this emerging topic. In their report from the iPOPY study on the impact of the trend towards organic sourcing for school food, He et al. ${ }^{(20)}$ suggest that such interventions might positively affect the attitudes, intentions and actions of school food coordinators towards improving the school eating environment.

\section{Future research needs in the area of school food}

The contributions to this issue of Public Health Nutrition show the wide range of challenges related to the school environment as an arena for promoting healthy eating. Besides more traditional approaches focusing on food intake and at-school lunches provided in cafeterias, canteens, etc., a number of other important aspects of the nutrition reality at schools are now under investigation. The contributions in this issue touch upon a wide range of topics including feasibility and implementation, the role of targeted fruit and vegetable programmes, breakfast programmes, challenges related to social inequality, the role of standards and official recommendations, and the clash between unhealthy and healthy options.

\section{Schools as foodscapes}

The articles in this issue also illustrate the complexity of the food environment that young people encounter in their daily life at school. I use the idea of foodscapes as a way to refer to capture and understand this diversity. Foodscapes studies (FSS), a growing area of research among scientists engaged in the study of foodways, offers an appropriate conceptual foundation for the holistic approach needed to understand the complex social system of the school and its opportunities for promoting good public health nutrition.

The concept of foodscapes draws from different sources. The idea of '-scapes' was put forward by Appadurai 
to capture interconnectedness through place and time. It was further developed by different scholars into the idea of 'foodscapes' and later into the idea of 'captive foodscapes' to illustrate the special importance of places where we eat regularly in 'captive' daily life, such as schools, kindergartens and institutions ${ }^{(21,22)}$, which are of special dietary importance due to the high frequency of eating there. The idea of school foodscapes takes inspiration from Gibson's notion of affordances ${ }^{(23,24)}$, which argues that the environment offers 'action possibilities' - in the case of school food, possibilities for promoting healthy eating through foodservice and learning. These possibilities exist in relation to the agents and as a result are dependent on the agents' ability and willingness to recognize these capabilities. The idea of foodscapes further draws on the capabilities approach that originates from work of Nussbaum and Sen ${ }^{(25)}$ to describe how the full potentials of individuals can be tapped in welfare systems through the provision of rights.

As such, we can understand the captive foodscape of the school as a meso food environment consisting of structures and agents, and in which food, people and space interact in particular ways and become promoters of good habits within eating, serving and socializing among young people. By adding meaning and power to it we can understand it as a powerful setting for intervention - meaning because school is increasingly recognized as a meaningful place to intervene by a broad range of stakeholders, and power because it is increasingly recognized as a place where there is also political support to intervene.

\section{Dealing with complexity: the broad range of challenges and approaches}

The contributions to this issue also show clearly the diversity of national approaches to school feeding. They range from a collective approach, in which the welfare system provides free and tax-paid school lunches such as those found in Sweden and Finland, to a semi-collective approach with family-paid lunches as found in France and the UK, to non-collective approaches with no national obligation to provide school lunch and relying on local and/or commercial initiatives, as found in Denmark, the Netherlands and Norway. The contributions in this issue illustrate the variety of challenges related to food, nutrition and eating at school, as well as the strategies that can be applied in order to use the school environment as a platform for public health nutrition. Finally, the articles show the complexity of different aspects of the school food system and the range of different stakeholders that need to be taken into account if this system should be used to promote health through food and eating. As such, the growing body of research in this field seems to suggest that in many cases researchers are forced to reduce complexity in the way school food systems are viewed and evaluated. The call for evidence often tend to favour measurements that look at the impact of single intervention components instead of at the totality.

\section{Advantage of the foodscape approach}

Using a foodscape approach implies taking a broader view and linking all the different aspects into one single model to address the different components in one multilayered intervention; in short, an ecological approach that treats the in- and out-of-school determinants in students' food environments. Although they are by definition much more difficult to address due to their open and unregulated architecture, the influences of these determinants on students' dietary behaviour need to be taken into account as a whole. Coherent strategies to influence the eating patterns of children and adolescents need to address the totality of these influences.

The foodscape approach acknowledges that students are influenced by and take food and meals from multiple sources at school - not only the foods offered as part of an SMP, but also foods offered in separate school fruit schemes, foods found in other venues such as vending machines and tuck shops, and packed lunches and snacks brought from home. In addition, students encounter food in material form as well as in imagery on their way to and from school, in the family sphere, and in the complex mediascapes that surround young people. Thus, there is a need for research that examines how healthy foodscapes can be extended beyond the school premises and into the local community.

\section{Conclusion}

Public health nutrition research has an important role to play in informing current and future populationbased school food policies and strategies. This requires a holistic approach to the science of food and nutrition at school and should encompass the broad and complex social systems of the school and its environment. Such a holistic approach also implies a shift from looking exclusively at the school and instead broadening our examination of the full range of food realities that young people meet. By taking the food perspective of pupils as the point of departure, research should look at the question of eating from all the different platforms where young people encounter food, nutrition and eating in a broad sense during their everyday life at school.

\section{Acknowledgements}

Thanks go to Assistant Professor Jose A. Torralba, Curriculum Studies at the University of Hawaii at Manoa, for valuable comments on the manuscript.

Bent Egberg Mikkelsen Email: bemi@plan.aau.dk First Editor 


\section{References}

1. Council of Europe (2005) Resolution on healthy eating at school. http://www.coe.int/t/e/social_cohesion/soc-sp/ public_health/nutrition_food_consumer_health/Resolution $\%$ 20AP-2005-3\%20HEALTHY\%20EATING\%20SCHOOLS.asp

2. Nordic Council of Ministers (2006) A Better Life through Diet and Physical Activity. Nordic Action Plan on Better Health and Quality of Life through Diet and Physical Activity. Copenhagen: Nordic Council of Ministers; available at http://www.norden.org/en/publications/ publikationer/2006-746/at_download/publicationfile

3. World Health Organization (2006) European Charter on Counteracting Obesity. WHO European Ministerial Conference on Counteracting Obesity, Istanbul, Turkey, 15-17 November 2006. Copenhagen: WHO Regional Office for Europe; available at http://www.euro.who.int/ __data/assets/pdf_file/0009/87462/E89567.pdf

4. Commission of the European Communities (2007) White Paper: A Strategy for Europe on Nutrition, Overweight and Obesity Related Health Issues. Brussels: Commission of the European Communities; available at http://ec.europa. $\mathrm{eu} /$ health/ph_determinants/life_style/nutrition/documents/ nutrition_wp_en.pdf

5. World Food Programme (2013) State of School Feeding Worldwide 2013. Rome: WPF; available at http://documents. wfp.org/stellent/groups/public/documents/communications/ wfp257481.pdf

6. Sonnino R \& Morgan K (2007) The School Food Revolution: Public Food and the Challenge of Sustainable Development. London: Earthscan.

7. Nelson M (2011) The School Food Trust: transforming school lunches in England. Nutr Bull 36, 381-389.

8. Ribeiro RQC \& Alves L (2014) Comparison of two schoolbased programmes for health behaviour change: the Belo Horizonte Heart Study randomized trial. Public Health Nutr 17, 1195-1204.

9. Caparosa SL, Shordon M, Santos AT et al. (2014) Fundraising, celebrations and classroom rewards are substantial sources of unhealthy foods and beverages on public school campuses. Public Health Nutr 17, 1205-1213.

10. Faber M, Laurie S, Maduna M et al. (2014) Is the school food environment conducive to healthy eating in poorly resourced South African schools? Public Health Nutr 17, 1214-1223.

11. Øvrum A \& Bere E (2014) Evaluating free school fruit: results from a natural experiment in Norway with representative data. Public Health Nutr 17, 1224-1231.

12. Bucher T, Siegrist M \& van der Horst K (2014) Vegetable variety: an effective strategy to increase vegetable choice in children. Public Health Nutr 17, 1232-1236.
13. Just D \& Price J (2013) Default options, incentives and food choices: evidence from elementary-school children. Public Health Nutr 16, 2281-2288.

14. Valaitis RF, Hanning RM \& Herrmann IS (2014) Programme coordinators' perceptions of strengths, weaknesses, opportunities and threats associated with school nutrition programmes. Public Health Nutr 17, 1245-1254.

15. Smith SL \& Cunningham-Sabo L (2014) Food choice, plate waste and nutrient intake of elementary and middle-school students participating in the US National School Lunch Program. Public Health Nutr 17, 1255-1263.

16. Rocha A, Afonso C, Santos MC et al. (2014) System of planning and evaluation of school meals. Public Health Nutr 17, 1264-1270.

17. Sahota JW, Molinari R \& Pike J (2014) Factors influencing take-up of free school meals in primary- and secondaryschool children in England. Public Health Nutr 17, 1271-1279.

18. Moore GF, Murphy S, Chaplin K et al. (2014) Impacts of the Primary School Free Breakfast Initiative on socioeconomic inequalities in breakfast consumption among 9-11-year-old schoolchildren in Wales. Public Health Nutr 17, 1280-1289.

19. Vine MM \& Elliott SE (2014) Examining local-level factors shaping school nutrition policy implementation in Ontario, Canada. Public Health Nutr 17, 1290-1298.

20. He C, Perez-Cueto FJA \& Mikkelsen BE (2014) Do attitudes, intentions and actions of school food coordinators regarding public organic food procurement policy improve the eating environment at school? Results from the iPOPY study. Public Health Nutr 17, 1299-1307.

21. Mikkelsen BE (2011) Images of foodscapes: introduction to foodscape studies and their application in the study of healthy eating out-of-home environments. Perspect Public Health 131, 209-216.

22. Torralba JA \& Guidalli BA (2014) Developing a conceptual framework for understanding children's eating practices in different foodscapes: implications for school food reform. Paper presented at the International Conference on Food, Children and Youth: What's Eating? Lisbon, Portugal, 21-22 February 2014.

23. Gibson JJ (1977) The theory of affordances. In Perceiving, Acting, and Knowing: Toward an Ecological Pyschology, pp. 67-82 [R Shaw and J Bransford, editors]. Hillsdale, NJ Laurence Erlbaum

24. Gibson JJ (1986) The Ecological Approach to Visual Perception. New York: Psychology Press.

25. Nussbaum MC \& Sen A (editors) (1993) The Quality of Life. Oxford: Clarendon Press. 